\title{
BJMHR
}

British Journal of Medical and Health Research

Journal home page: www.bjmhr.com

\section{Seminal Plasma concentrations of Semenogelin and Zinc Among infertile males and their association with Asthenozoospermia.}

\author{
Muyiwa Adeleye Moronkeji ${ }^{1,2}$, Mathias Abiodun Emokpae ${ }^{1^{*}}$ \\ 1. Department of Medical Laboratory Science, School of Basic Medical Sciences, \\ University of Benin, Benin City. \\ 2. Department of Chemical Pathology, Ladoke Akintola University of Science and \\ Technology Teaching Hospital, Osogbo, Nigeria.
}

\section{ABSTRACT}

Poor semen liquefaction is one of the causes of male infertility which has become a public health challenge in Nigeria. Abnormal sperm motility is one of the commonest abnormalities detected in infertile males. The pathogenesis of poor liquefaction and solidification of semen are modulated by Semenogelin and some other secretions from male accessory organs. To evaluate the concentrations of Semenogelin and zinc in seminal plasma and to correlate the levels with percentage sperm motility. Four hundred men, mean age $36.4 \pm 6.8$ years who were evaluated for infertility and 100 men, mean age $40.2 \pm 6.6$ years of proven fertility were consecutively recruited for the study. Following routine semen analysis, seminal plasma Semenogelin-1 and zinc were determined by ELISA technique and Atomic Absorption spectrophotometry techniques respectively. Data generated were compared between groups and association between Semenogelin, zinc and percentage sperm motility was determined. Seminal plasma Semenogelin level was higher $(\mathrm{p}<0.001)$ in infertile males irrespective of the sperm concentration than controls. On the other hand, seminal plasma zinc level was lower $(\mathrm{p}<0.001)$ among oligozoospermia and azoospermia than controls. The mean Semenogelin level was significantly higher $(\mathrm{p}<0.001)$ among asthenozoospermia than those with normal percent motility while mean seminal plasma zinc level in asthenozoospermia was lower $(\mathrm{p}<0.001)$ than those with normal percentage motility. Seminal plasma Semenogelin $(\mathrm{R}=-$ $0.217 ; \mathrm{p}<0.005)$ correlated negatively with asthenozoospermia and zinc $(\mathrm{R}=-0.148 ; \mathrm{p}<0.05)$ but zinc correlated $(\mathrm{R}-0.150 ; \mathrm{p}<0.05)$ positively with asthenozoospermia. Alterations in the levels of Semenogelin and zinc are associated with asthenozoospermia among infertile males.

Keywords: Male infertility, Sperm motility, Semenogelin, zinc. 


\section{INTRODUCTION}

An estimated $15 \%$ of couples of reproductive age fail to achieve pregnancy within one year of regular unprotected sexual intercourse all over the world. Male infertility associated factors are responsible for about $50 \%$ of these cases and abnormal levels of seminal fluid proteins and trace elements could be implicated. Seminal plasma Semenogelin and zinc levels have been associated in male fertility potentials ${ }^{1}$. They have been reported to offer a wide range of information on the functional status of the entire male reproductive system. Semen analysis still forms the bedrock of the early investigations of male infertility, but the procedure remains imperfect in predicting fertility potentials ${ }^{2}$. There may be infertile men in whom there is a defect in one of the tasks that are very vital for spermatozoa to transverse the female reproductive tract to reach and fertilize an ovum. This is may not be detected by routine semen analysis. Such group consists of up to $40-50 \%$ of subfertile men ${ }^{3}$. It is therefore imperative to determine their levels in seminal plasma of men with infertility and association with sperm motility.

Semen liquefaction is one of the causes of male infertility and it refers to the inability of ejaculated semen to liquefy within one hour ${ }^{4}$. The pathogenesis of abnormal semen liquefaction is not completely understood, but it is generally believed that semen liquefaction and solidification are modulated by Semenogelin ${ }^{5}$, a secretion of the seminal vesicles. The abnormal semen liquefaction can occur due to increased levels of Semenogelin, seminal vesiculitis, deficiency of zinc and magnesium as well as congenital deficiencies of the prostate and reduced prostate secretion ${ }^{6,7}$. Semenogelins are components of human semen coagulum produced by seminal vesicle and are made up two related proteins (Semenogelin 1 and Semenogelin 2). The proteins are responsible for sperm immobilization in the seminal coagulum $^{8}$. It represents the most abundant seminal proteins and play vital role in sperm physiology, probably at different time point as the spermatozoa travel down the female genital tract. The physiological function ascribed to Semenogelin are regulation of sperm motility and capacitation, a series of transformations that spermatozoa undergo as they migrate in the female genital tract in order to reach, bind and fertilize the ovum $)^{1}$.

Zinc is second most abundant element in human tissues and is excreted from the prostate gland as a low-molecular-weight complex. It is estimated that the zinc levels in seminal plasma may entirely represent prostatic secretory function. After ejaculation, about $50 \%$ of the amount in the complex is redistributed and linked to medium- and high-molecular-weight compounds such as Semenogelin generated from the seminal vesicles ${ }^{9}$. In the human reproductive system, $\mathrm{Zn}$ plays an essential role in spermatogenesis, from its primitive stage to maturation, contributes to the ultrastructural stabilization of chromatin compaction, regulation of the 
mitochondria-dependent processes, such as cell respiration and apoptosis ${ }^{10,11}$. Zinc is also acts as cofactor for DNA-binding proteins with $\mathrm{Zn}$ fingers. It is a part of copper $(\mathrm{Cu}) / \mathrm{zinc}$ superoxide dismutase, and several proteins that are involved in the repair of damaged DNA ${ }^{12}$. The objective of this study was to evaluate the concentrations of seminal plasma Semenogelin1 , zinc and their correlation with asthenozoospermia among infertile males.

\section{MATERIALS AND METHOD}

\section{Study participants and study design:}

This is a cross sectional study of males who were investigated for infertility. They consist of 400 men, mean age 36.4 \pm 6.8 years (rage;21-60) who were consecutively recruited between November 2017 and July 2019 from infertility clinics in Osogbo, Osun State, Nigeria. The control group was 100 men, mean age 40.2 \pm 6.6 years (range; 22-59) who have had babies within the past one year. All males investigated for infertility were grouped according to semen parameters as normozoospermia (spermatozoa count $\geq 15 \times 10^{6} / \mathrm{mL}$ ), oligozoospermia (spermatozoa count $0.1-14.9 \times 10^{6} / \mathrm{mL}$ ) and azoospermia (absence of sperm cells) as well as percent asthenozoospermia and percent teratozoospermia.

\section{Ethical Consideration}

The study protocol was reviewed and approved by the Health Research Ethics Committee of Osun State Ministry of Health, Abere, Osogbo, Osun State (Ref. OSHREC/PRS/569/149) dated $30^{\text {th }}$ November, 2017. All study participants gave informed consent to participate in the study before they were enlisted.

\section{Inclusion Criteria}

All male subjects aged 21-60years who were evaluated for infertility, gave consented, without physical abnormalities or chronic illnesses were included in the study. Subjects without chronic clinical illnesses and had their babies within the last one year, whose seminal fluid analysis showed over 15 million sperm cells per milliliter according to WHO criteria [13] were included and used as controls.

\section{Exclusion Criteria}

Individuals with known pathological or congenital conditions such as severe hypertension, diabetes mellitus, sexually transmitted diseases, testicular varicocele and genital warts were excluded. In addition, individuals currently on antioxidant supplementation, smokers and alcoholics were also excluded due to their high seminal reactive oxygen species levels and possibly low antioxidant activity which might lead to decreased motility and abnormal sperm morphology.

\section{Sample size:}


The sample size (n) was calculated using estimated prevalence of $40 \%$ from previous study on male infertility in Nigeria (14) and sample size determination formula by Lwange and Lemeshow(15). $\mathrm{N}=\mathrm{Z}^{2}(1-\mathrm{P}) \mathrm{P} / \mathrm{d}^{2}$. The calculated sample size was 369 which was increased to 400 for the purpose of this study.

\section{Laboratory Analysis}

\section{Specimen collection:}

Semen samples were collected by self or assisted masturbation after 3-5days sexual abstinence. Specimens were submitted to the laboratory within 30 minutes and were allowed to liquefy at room temperature. Manual semen analysis was done according to WHO criteria ${ }^{13}$.

\section{Seminal Plasma:}

After liquefaction and semen analyses done, the sample was centrifuged at $3000 \mathrm{rpm}$ for 5 minutes and the supernatant was separated into sterile vacutainer plain and store at $-80^{\circ} \mathrm{C}$ until biochemical analyses were performed.

\section{Human Semenogelin-1 Assay (Cusabio Biotechnology, Wuhan, China) Principle:}

The assay employs the quantitative sandwich enzyme immunoassay technique. Antibody specific for SEMG1 has been pre-coated onto a microplate. After removing any unbound substances, a biotin-conjugated antibody specific for SEMG1 is added to the wells. After washing, avidin conjugated Horseradish peroxidase (HRP) is added to the wells. Following a wash to remove any unbound avidin-enzyme reagent, a substrate solution is added to the wells and colour develops in proportion to the amount of SEMG1 bound in the initial step. The color development is stopped and the intensity of the color is measured. The values were read from standard curve previously determined.

\section{Seminal plasma Zinc Determination:}

The seminal plasma zinc was determined using Atomic Absorption Spectrometry (AAS) ${ }^{16}$. The mean of duplicate testing was used for data analysis.

\section{Statistical Analysis:}

The data generated from the study were compared between the groups using unpaired Students-t-test and One way analysis of variance (ANOVA) as appropriate by statistical software SPSS version 21 (SPSS Inc, Chicago, IL, USA). A p-value $\leq 0.05$ was considered statistically significant.

\section{RESULTS AND DISCUSSION}

The sperm quality results indicate that $170(47.4 \%)$ had normal percentage motility while $189(52.6 \%)$ had percentage motility $<40 \%$ (asthenozoospermia). The percentage motility was higher $(\mathrm{p}<0.001)$ among those with percentage motility $\geq 40$ than those with 
asthenozoospermia. Those with teratozoospermia 99(27.6\%) had percentage morphology lower $(\mathrm{p}<0.001)$ than those with normal percentage morphology. Similarly those with semen volume $\geq 1.5 \mathrm{~mL}$ was significantly higher than those with volume $<1.5 \mathrm{~mL}$. Table 2 shows the comparison of seminal plasma Semenogelin and zinc levels among asthenozoospermic subjects and normal percentage motility. Seminal plasma mean Semenogelin level was significantly higher $(\mathrm{p}<0.001)$ among asthenozoospermia than those with normal percent motility. Conversely, mean seminal plasma zinc level in asthenozoospermia was significantly lower $(\mathrm{p}<0.001)$ than those with normal percentage motility. Seminal plasma Semenogelin level was higher $(\mathrm{p}<0.001)$ in infertile males irrespective of the sperm concentration when compared with controls. On the other hand, seminal plasma zinc level was lower $(\mathrm{p}<0.001)$ among oligozoospermia and azoospermia than controls. The level in normozoospermia was not significantly different from controls. Seminal plasma Semenogelin $(R=-0.217 ; p<0.005)$ correlated negatively with asthenozoospermia and zinc $(\mathrm{R}=-0.148 ; \mathrm{p}<0.05)$ but zinc correlated (R-0.150;p<0.05) positively with asthenozoospermia.

Table 1: Classification Sperm Indices among males investigated for infertility based on WHO Criteria 2010

\begin{tabular}{llll}
\hline Sperm Indices & Frequency (\%) & Mean(SD) & P-value \\
\hline Sperm Concentration $\left(\times 10^{6} / \mathrm{mL}\right)$ & & & \\
Normozoospermia $\left(\geq 15 \times 10^{6} / \mathrm{mL}\right)$ & $191(47.8)$ & $67.2 \pm 3.49$ & \\
Oligozoospermia $\left(0.1-14.9 \times 10^{6} / \mathrm{mL}\right)$ & $168(42)$ & $7.56 \pm 2.81$ & 0.001 \\
Total motility (\%) & & & \\
Normal ( $\geq 40 \%)$ & $170(47.4)$ & $44.2 \pm 0.5$ & \\
Asthenozoospermia (0-39\%) & $189(52.6)$ & $21.2 \pm 0.6$ & 0.001 \\
Sperm morphology (\%) & & & \\
Normal (>4\%) & $260(72.4)$ & $6.7 \pm 0.2$ & \\
Teratozoospermia(0-3\%) & $99(27.6)$ & $3.1 \pm 0.5$ & 0.001 \\
Volume (mL) & & & \\
$>1.5 \mathrm{~mL}$ & $386(96.5)$ & $3.02 \pm 1.6$ & \\
$<1.5 \mathrm{~mL}$ & $14(3.5)$ & $1.2 \pm 0.02$ & 0.001 \\
\hline
\end{tabular}

Table 2: Comparison of Seminal Plasma Semenogelin and zinc levels among infertile males and Control subjects

\begin{tabular}{lllll}
\hline Parameters & \multicolumn{2}{l}{$\begin{array}{l}\text { Asthenozoospermia } \\
\text { 0-39\% }\end{array}$} & Control subjects & P-value \\
\hline Age (Years) & $37.2 \pm 4.6^{\mathrm{a}}$ & $36.9 \pm 5.2^{\mathrm{a}}$ & $40.2 \pm 6.6$ & 0.05 \\
Number of subjects & 189 & 170 & 100 & \\
Semenogelin(ng/mL) & $3.78 \pm 0.5$ & $1.47 \pm 0.28^{\mathrm{a}}$ & $1.42 \pm 0.3$ & 0.001 \\
Zinc $(\mu \mathrm{g} / \mathrm{mL})$ & $0.81 \pm 0.01$ & $2.06 \pm 0.08^{\mathrm{a}}$ & $2.08 \pm 0.02$ & 0.001 \\
\hline
\end{tabular}
$\mathrm{a}=\mathrm{p}>0.05$. 
Table 3: Comparison of seminal plasma Semenogelin and zinc according to fertility subtypes

\begin{tabular}{llll}
\hline Fertility Subtypes & N & $\begin{array}{l}\text { Semenogelin }(\mathbf{n g} / \mathbf{m L} \\
\text { ) mean } \pm \text { SD }\end{array}$ & $\begin{array}{l}\text { Zinc }(\boldsymbol{\mu g} / \mathbf{m L}) \\
\text { mean } \pm \text { SD })\end{array}$ \\
\hline Normozoospermia $\left(\geq 15 \times 10^{6} / \mathrm{mL}\right)$ & 191 & $3.21 \pm 0.6$ & $2.10 \pm 0.6$ \\
Oligozoospermia $\left(0.1-14.9 \times 10^{6} / \mathrm{mL}\right)$ & 168 & $3.82 \pm 0.5$ & $1.98 \pm 0.5$ \\
Azoospermia(Absence of sperm cells) & 41 & $3.62 \pm 0.8$ & $1.73 \pm 0.6$ \\
Controls & 100 & $2.47 \pm 0.2$ & $2.16 \pm 0.4$ \\
P-value & & 0.001 & 0.001 \\
\hline
\end{tabular}

Table 4: Correlation of Semenogelin, zinc with asthenozoospermia among infertile subjects

\begin{tabular}{lll}
\hline Correlation & R & P-value \\
\hline Semenogelin vs Asthenozoospermia & -0.217 & 0.005 \\
Semenogelin vs Zinc & -0.148 & 0.05 \\
Zinc vs Asthenozoospermia & 0.150 & 0.05 \\
\hline
\end{tabular}

\section{DISCUSSION}

The ability of routine semen analysis to accurately predicts male fertility potential has been a subject of debates ${ }^{3}$, especially among subjects with normozoospermia but infertile. This has led to the development of other biomarkers that could be used in the diagnosis of abnormal molecular mechanisms that control the function and competence of human spermatozoa. Ejaculated semen suddenly coagulates to form semi-solid gelatinous meshwork of narrow and long fibres of which semenogelins are the major components that immobilize spermatozoa ${ }^{1}$. This gelatinous scaffold is quickly degraded into low molecular mass proteins by prostate specific antigen (PSA) to allow spermatozoa to move ${ }^{17}$. This action is not however dependent on seminal hyperviscosity since semenogelins do not prevent sperm motility via viscosity but a fragment of the degradation product called Seminar plasma motility inhibition product ${ }^{1}$ ). In this study, seminal plasma Semenogelin concentration was higher among oligospermia and azoospermia than controls. The concentration correlated negatively with asthenozoospermia among infertile males. This finding is consistent with previous study in which an inverse association was observed between Semenogelin and spermatozoa of infertile males with asthenozoospermia ${ }^{18}$. Several authors have reported the role play by Semenogelins in the physiological function of control of motility and capacitation ${ }^{19-22}$. Some have reported other potential uses of Semenogelin to include the choice of selection of a most suitable method of assisted reproductive technology and in the decision to use in-vitro fertilization (IVF) or intracytoplasmic sperm injection (ICSI) instead of intrauterine insemination. Several hypotheses have been postulated to explain how Semenogelins hinder spermatozoa movement within the female genital tract. Zinc ion instigates coagulation as it binds to Semenogelin and in the process brings about some conformation changes thereby making the spermatozoa to 
bind to one another and hinder sperm motility ${ }^{23}$. It was also suggested that Semenogelin can bind to spermatozoa membrane via its phospholipids and thus allows the passage of zinc ions which ultimately immobilize spermatozoa ${ }^{1}$. It is possible Semenogelins bind to membrane receptors, a process that triggers several biological activities that hinder sperm motility.

Seminal plasma zinc level was significantly lower among infertile males than controls and correlated positively with asthenozoospermia. Some studies also reported that the seminal plasma zinc concentrations from infertile patients were significantly lower than those from normal controls ${ }^{24-27}$. One study reported that the zinc concentration in the seminal plasma from infertile men was significantly higher than that in normal men ${ }^{28}$, and some other studies showed no significant difference between infertile and normal males ${ }^{29-31}$. An association between zinc and sperm motility was also reported by Sorenson et al ${ }^{10}$. It has been suggested that the high binding capacity of Semenogelin and its byproducts to zinc ion is vital for the regulation of PSA activity and enhances the binding of Semenogelin to spermatozoa proteins in cells free assays as well as the movement of zinc ion to sperm nucleus to support DNA stability ${ }^{32,33}$. Changes in semenogelin and zinc levels may impact on spermatozoa functions. Zinc is the most common inorganic ions present in seminal plasma and acts as cofactor or inhibitor for several proteolytic enzymes involved in the coagulation-liquefaction process

\section{CONCLUSION:}

Seminal plasma Semenogelin concentration was higher among infertile males than controls while zinc was lower among infertile males than control subjects. There was an inverse relationship between asthenozoospermia and Semenogelin while zinc level correlated positively with asthenozoospermia. It is possible that changes in Semenogelin and zinc concentrations might be partly responsible for asthenozoospermia among infertile males.

\section{ACKNOWLEDGEMENTS:}

We appreciate the contributions of all the physicians, Nurses and Medical Laboratory Scientists towards the completion of this study.

\section{CONFLICTS OF INTEREST:}

None declared

An association was found between high zinc concentrations and low linearity of sperm movements as expressed by a decrease in

\section{REFERENCES}

1. Yamasaki K, Yoshida K, Yoshiike M, Shimada K, Nishiyama H, Takamizawa S, Yanagida K, Iwamoto T. Relationship between Semenogelins bound to human sperm and other semen parameters and pregnancy outcomes. Basic Clin Androl, 2017; 27:15 
2. Jungwirth A, Diemer T, Dohle GR, Giwercman A, Kopa Z, Krausz C, Tournaye H. Guidelines for Male Infertility. In: European Association of Urology 2012.https://uroweb.org/wp-content/uploads/17-Male-Infertility_LR1.pdf.Accessed 24 Mar 2020.

3. Esteves SC, Sharma RK, Gosalvez J, Agarwal A. A translational medicine appraisal of specialized andrology testing in unexplained male infertility. Int Urol Nephrol. 2014;46:1037-1052.

4. Aitken RJ. Sperm function tests and fertility. Int J Androl 2006;29(1):69-75.

5. Chen Z, Song T, Chen C, Liu T, Wen, Yao Y, Zou C, Li X, Xu Q, Mao K. ChenghongProdom: a new assisted reproductive device to treat male infertility caused by impaired semen liquefaction. Int J Clin Exp Med 2019;12(4):4088-4099

6. Liu FX, Su DL, Zhu GY. [Abnormal semen liquefaction and seminal plasma lipoprotein (a)]. Zhonghua Nan Ke Xue 2013; 19: 247-250.

7. Yoshida K, Yamasaki T, Yoshiike M, Takano S, Sato I, Iwamoto T. Quantification of seminal plasma motility inhibitor/semenogelin in human seminal plasma. J Androl 2003; $24: 878-84$.

8. Lilja H, Abrahamsson PA, Lundwall A. Semenogelin, the predominant protein in human semen. Primary structure and identification of closely related proteins in the male accessory sex glands and on the spermatozoa. J Biol Chem. 1989;264:1894-900.

9. Zhao J, Dong X, Long Z, Wang L, Liu Q, Sun B, Wang Q, Wu Q, Li L.. Zinc levels in seminal plasma and their correlation with male infertility: A systematic review and meta-analysis. Sci. Rep. 6, 22386.

10. Sorensen MB, Bergdahl IA, Hjollund NI, Bonde JP, Stoltenberg M, Ernst E. Zinc, magnesium and calcium in human seminal fluid: relations to other semen parameters and fertility. Mole Hum Reprod 1999; 5(4): 331-337.

11. Smith AF, Longpre J, Loo G. Inhibition by zinc of deoxycholate-induced apoptosis in HCT-116 cells. J Cell Biochem ,2012;113: 650-657.

12. Ho E and Ames BN. Low intracellular Zinc induces oxidative DNA damage, disrupts P53, NFאB, and AP1 DNA binding, and affects DNA repair in a rat glioma cell line. Cell Biol 2002; 99:16770-1675.

13. World Health Organization. WHO laboratory manual for the examination and processing of human semen, 5th edn. Geneva: World Health rganization, 2010.

14. Uadia PO, Emokpae AM. Male infertility in Nigeria:A neglected reproductive health issue requiring attention. J Basic Clin Reprod Sci 2015;4:45-53.

15. Lwange SK and Lemeshow S. Sample size determination in health studies; a practical manual. IRIS, World Health Organization, 1991. 
16. Alvarado J, Moreno R, Cristiano AR. Determination of $\mathrm{Cd}, \mathrm{Cr}, \mathrm{Cu}, \mathrm{Pb}$ and $\mathrm{Zn}$ in Human Semen by Graphite Furnace Atomic Absorption Spectrometry After Microwave Sample Dissolution. J Trace Elem Electrolytes Health Dis, 1991; 5(3):173-180.

17. Yoshida K, Iwamoto T, Yoshida M. Effects of the seminal plasma proteins semenogelin (SEMG)/seminal vesicle secretion 2 (SVS2) on sperm fertility. In: Lejeune T, Delvaux P, editors. Human Spermatozoa: Maturation, Capacitation and Abnormalities. NY: Nova Science Publishers; 2010. p. 205-220.

18. Terai K, Yoshida K, Yoshiike M, Fujime M, Iwamoto T. Association of seminal plasma motility inhibitors/semenogelins with sperm in asthenozoospermia infertile men. Urol Int. 2010;85:209-215.

19. . Esfandiari N, de Lamirande E, Guktulket A, San Gabriel MC, Nazemian Z,Burjaq H, et al. Seminal hyperviscosity is not associated with Semenogelin degradation or sperm deoxyribonucleic acid damage: a prospective study of infertile couples. Fertil Steril. 2014;101:1599-1603.

20. Yoshida K, Krasznai ZT, Krasznai Z, Yoshiike M, Kawano N, Yoshida M, et al. Functional implications of membrane modification with semenogelins for inhibition of sperm motility in humans. Cell Motil Cytoskeleton. 2009;66:99-108.

21. Yoshida K, Kawano N, Yoshiike M, Yoshida M, Iwamoto T, Morisawa M. Physiological roles of semenogelin I and zinc in sperm motility and semen coagulation on ejaculation in humans. Mol Hum Reprod. 2008;14:151-156.

22. de Lamirande E, Yoshida K, Yoshiike TM, Iwamoto T, Gagnon C. Semenogelin, the main protein of semen coagulum, inhibits human sperm capacitation by interfering with the superoxide anion generated during this process. J Androl. 2001;22:672-679.

23. Robert M, Gagnon C. Semenogelin I: a coagulum forming, multifunctional seminal vesicle protein. Cell Mol Life Sci. 1999;55:944-960.

24. Xu X, He BJ, Zhao SM. Relationship between the levels of $\mathrm{Zn}, \mathrm{Cu}, \mathrm{Fe}, \mathrm{Mu}, \mathrm{Ni}$ in seminal plasma and male infertility. J Ningxia Medl Coll.1997; 19:13-16.

25. Zhang, DT, Liu Z, Liu YL. Clinical study of Zn complex glucose acid as an adjuvant drug for the treatment of the male infertility due to semen of poor quality. China J Urol ,2003;24: 564-567.

26. Zheng LP. The Comparative Analysis of Trace Elements in Blood and Seminal Plasma of Infertile and Healthy Male. Prog Modern Biomed,2012; 12:681-683.

27. Li P, Zhu X, Qin HY. Correlation between sperm quality and trance elements in infertile patients. Inter J Lab Med, 2012; 33: 659-660. 
28. Akinloye O(1), Abbiyesuku FM, Oguntibeju OO, Arowojolu AO, Truter EJ. The impact of blood and seminal plasma zinc and copper concentrations on spermogram and hormonal changes in infertile Nigerian men. Reprod Biol,2011; 11:83-98.

29. Türk S, Mändar R, Mahlapuu R, Viitak A, Punab M, Kullisaar T. Male infertility: decreased levels of selenium, zinc and antioxidants. J Trace Elem Med Biol 28, 17985 (2014).

30. Fuse H, Kazama T, Ohta S, Fujiuchi Y. Relationship between zinc concentrations in seminal plasma and various sperm parameters. Int Urol Nephrol,1999; 31: 401-408.

31. Colagar A H, Marzony ET, Chaichi MJ. Zinc levels in seminal plasma are associated with sperm quality in fertile and infertile men. Nutr Res,2009; 29: 82-88.

32. Yoshida K, Krasznai ZT, Krasznai Z, Yoshiike M, Kawano N, Yoshida M et al. T Functional implications of membrane modification with semenogelins for inhibition of sperm motility in humans. Cell Motil Cytoskeleton 2009;66: 99-108.

33. Jonsson M, LundwallA, Malm J. The semenogelins: proteins with functions beyond reproduction? Cell Mol Life Sci 2006;63:2886-2888.

34. Drabovich AP, Saraon P, Jarvl K, Diamandis EP. Seminal plasma as a diagnostic fluid for male reproductive system disorders. Nature Rev Urol 2014;11:278-288.

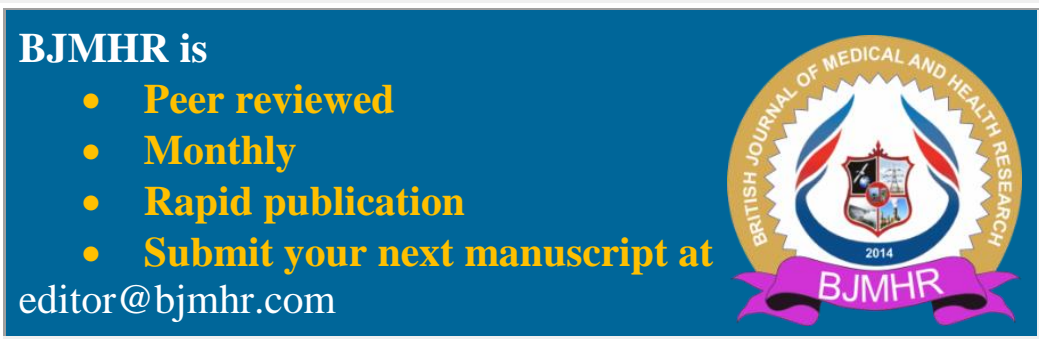

